\title{
ANTROPOMORFISMO E O ESPAÇO METAFÓRICO NAS NARRATIVAS LITERÁRIAS EM LÍNGUA DE SINAIS
}

\author{
ANTHROPOMORPHISM AND METAPHOR SPACE IN LITERARY \\ NARRATIVES IN SIGN LANGUAGE \\ ANTROPOMORFISMO Y EL ESPACIO METAFÓRICO EN LAS NARATAS \\ LITERARIAS EN LENGUA DE SEÑALES
}

Sofia Oliveira Pereira Anjos- Coimbra*

\section{Resumo}

A Literatura Surda utiliza a língua de sinais para repercutir temas e formas linguísticoculturais da comunidade Surda, uma comunidade que se expressa por meio da visualidade e do corpo. Tendo como principal referência os estudos desenvolvidos por Sutton-Spence e Napoli sobre o antropomorfismo e o espaço metafórico na Literatura Surda, este artigo analisa duas narrativas produzidas por contadores de histórias surdos em LSB, Língua de Sinais do Brasil e BSL, Língua de Sinais Britânica, buscando nelas identificar esses dois processos linguísticos, a antropomorfia e o espaço metafórico. $\mathrm{Na}$ análise das narrativas nos valemos da identificação dos processos e sua quantificação. Este estudo demonstra que o processo da antropomorfia, baseado em incorporações, é o mais recorrente nas narrativas analisadas. $\mathrm{O}$ espaço metafórico aparece sutilmente, mas pode estar presente a depender da divisão espacial atribuída pelo contador da história.

Palavras-chave: Literatura Surda. Narrativas em LS. Antropomorfia. Espaço metafórico.

A Literatura é uma forma de expressão linguística e performática, privilegiada para a transmissão da história e da cultura de um povo, por deter reflexões sobre o comportamento humano. Em todos os países, comunidades surdas encontram na produção de literatura surda uma forma de explicitar e perpetuar seus valores históricos e culturais, compartilhando sua perspectiva de mundo através da sua língua, a língua de sinais.

\footnotetext{
* Mestre em Linguística pela Universidade Federal de Goiás, UFG; Professora dos Cursos de Letras Libras e Letras Tradução e Interpretação Libras/Português na Faculdade de Letras, UFG. E-mail: sofiacoimbraanjos @gmail.com.
} 
Nas comunidades surdas, as línguas de sinais são constituídas em espaços sócioculturais bem determinados, tais como: associações de surdos, famílias de surdos ou escolas onde há alunos surdos, e permitem aos seus usuários a expressão e a transmissão de sua identidade, história e cultura. Assim como toda produção literária, a modalidade gesto-visual das línguas de sinais apresenta algumas características estético-linguísticas específicas. A produção literária nas línguas de sinais tem uma base visual e sua produção imagética de sentidos resulta em elementos estético-linguísticos distintos das línguas de modalidade oral, que têm uma base sonora para a produção de sentido.

Neste trabalho pretendemos analisar dois processos linguísticos que, de acordo com Sutton-Spence e Napoli, aparecem nas narrativas da literatura surda: antropomorfia e espaço metafórico, identificando qual o mais recorrente no gênero narrativo e avaliando como os contadores de histórias surdos utilizam tais processos, advindos dos princípios linguísticos da língua de sinais, contribuindo para a transmissão de valores socioculturais e para a valorização da língua por meio da literatura.

Ao se delimitar a pesquisa, optou-se pela análise de narrativas em duas línguas de sinais: LSB - Língua de Sinais Brasileira e BSL - Língua de Sinais Britânica. Buscamos analisar a antropomorfia e o espaço metafórico nessas narrativas, avaliando a recorrência de cada um dos processos estético-linguísticos estudados e como as escolhas linguísticas dos contadores de histórias contribuem para a linguagem literária dessas narrativas. Os textos escolhidos, disponíveis no youtube, são: "Owl” (Coruja), de Richard Carter e "Ping-Pong” de Rimar Ramalho.

\section{Literatura Surda}

Os surdos são sujeitos participantes de uma comunidade com características culturais e identitárias espelhadas em sua modalidade de língua, a língua de sinais. Ben Bahan (2006), poeta e pesquisador surdo, afirma que a História também ensina as pessoas surdas, dando-lhes sentido de identidade e de pertencimento, além de prover formas de interpretar e compreender o mundo coletivamente, garantindo assim a sobrevivência de sua cultura.

A literatura produzida por membros da comunidade surda irá inserir tanto o surdo como sua comunidade, numa perspectiva existencial, dando ao surdo consciência sobre si mesmo e sobre a sociedade que o cerca. O sujeito surdo apresenta similaridades 
básicas, assim como diferenças socioculturais e de interação, se comparado a outros grupos de indivíduos. Tais similaridades e diferenças contribuem para a constituição de um sujeito com uma história, subjetividade, identidade e cultura bem diferentes das expectativas preliminares resultantes do fato de ele nascer "desprovido de audição". Sobre essa questão, é preciso reconhecer que pode haver, dentro de uma comunidade surda, diferentes identidades surdas formadas pelo contato com a língua de sinais e os movimentos da comunidade. Assim, há diferentes níveis de surdez entre os surdos, o que gera diferentes identidades. Entretanto, a língua de sinais e a forma visual de comunicação são aspectos presentes nas constituições de todos os que se consideram surdos (CAMPELO, 2008; STROBEL, 2006).

Quando conhecemos o povo surdo, conhecemos todos os artefatos culturais que a condição de não ouvir lhes possibilitou. A expressão "povo surdo" segundo Strobel (2008, p.6) se refere "ao conjunto de sujeitos surdos que, embora não habitem no mesmo espaço, estão ligados por uma origem comum e por um código ético de formação visual que envolve: a língua de sinais, a cultura surda e qualquer outro laço".

Assim, surdos desenvolveram uma língua de base gesto-visual que explora as habilidades comunicativas da linguagem humana. Construíram ao longo do tempo uma história de conquistas e derrotas, de exclusão e inclusão, de preconceito e respeito. Por sua vez, os poetas e contadores de história surdos retomam o legado do passado, ao mesmo tempo em que vislumbram um futuro no qual questões de filosofia permeiam os temas que encontramos nas produções culturais dos surdos. Porém, por conta da barreira imposta, pela modalidade de língua, entre línguas orais-auditivas e gestovisuais, ou até mesmo por preconceitos cristalizados, pouco se conhece, ou se reconhece, da literatura surda.

Para reconhecer as reflexões dos surdos são necessárias aproximações, que requerem pertencimento à comunidade. É preciso conhecer sua história e compreender os fatores que construíram sua visão sobre o mundo. A língua de uma comunidade revela suas visões de mundo e concepções de vida. Dessa forma, a língua de sinais de um povo ou comunidade surda é construída e utilizada para satisfazer as necessidades humanas de cooperação e sobrevivência física, social e cultural desta comunidade. Silveira observa que "Nenhuma linguagem é neutra, nenhuma linguagem 'brota da 
natureza'... Ela é marcada pelas contingências pragmáticas, pelas práticas dos sujeitos que a criam e recriam continuamente" (2002, p. 20).

Nas famílias, associações ou clubes de surdos, instituições de ensino que agrupam surdos (APAES, CAS, Intitutos de terapia da linguagem...), o que se observa é que os surdos sempre se valeram de sua língua para contar histórias. Mourão observa que:

[...] há milhares de anos não existia escritas e as histórias circulavam somente pela oralidade, passando de geração em geração. No mesmo caminho os surdos utilizavam a sinalidade, passando de geração a geração histórias em línguas de sinais. No entanto, mesmo existindo obras e autores, é recente o uso da temática Literatura Surda, mesmo que os surdos contassem e recontassem histórias, narrativas, piadas e vários gêneros literários através da comunidade surda (2011, p.19).

A noção de Literatura Surda começou a circular nas escolas de surdos na Europa e nos Estados Unidos. No ano de 1864, quando a Universidade Gallaudet foi fundada, sujeitos surdos, acadêmicos e pesquisadores começaram a estudar a Literatura Surda e os que ali se formavam, levaram esses estudos para seus países de origem, assim como os significados culturais e identitários das análises sobre as produções surdas (Mourão, 2011 p.19).

Atualmente há grupos de poetas e autores individuais em diversos países que produzem literatura surda a partir do "deaflore" ou "folclore surdo", termo que, de acordo com Smith e Sutton-Spence (2007), une a palavra "deaf" com "lore". 0 termo "folclore", por sua vez, pode ser compreendido, de acordo com o Dicionário Aurélio Online como: "Ciência das tradições e usos populares"; "Conjunto das tradições, lendas ou crenças populares de um país expressas em danças, provérbios, contos ou canções" e “Cultura popular de um povo” (Holanda, 2017).

Desde 22 de agosto 1846, quando o pesquisador de cultura europeia, o inglês William John Thoms (1803-1885), cunhou o termo "folklore", rotulando os estudos até então identificados como "antiguidades populares" ou "literatura popular", esse conceito se ampliou. Podemos considerar o folclore como a essência de uma comunidade, por abranger diferentes esferas de sua existência, desde ações e situações diárias até a consciência coletiva sobre determinado fato ou experiência. Dessa forma, o 
folclore permite que, em uma comunidade, as gerações futuras possam refletir sobre suas identidades, bem como sobre sua cultura e subjetividade. De acordo com Bascom, citado por Sutton-Spence (2007, p. 45), o folclore geralmente funciona de quatro formas:

[...] firstly to express the culture of the group, secondly to justify group behavior to outsiders, thirdly to educate group members about the values and norms of the group and fourthly to maintain those expected ways of behaving. The four can be summarized under the single function of maintaining the stability of culture ${ }^{1}$.

Neste sentido, o termo "deaflore" designa o folclore da comunidade surda. Os termos "deaflore" e "signlore" foram cunhados por Simon Carmel, há mais de 20 anos nos Estados Unidos. Segundo Carmel (1996), deaflore refere-se ao conjunto de poemas, piadas, lendas, enigmas, narrativas, dentre outras produções que utilizam jogos de linguagem para transmitir o folclore surdo. A partir da produção literária de base deaflore, temos o uso da linguagem visuo-espacial-corporal voltado para a forma, ou seja, o "singlore", expressão que Carmel (1996) define como o uso da língua para expressão do folclore de uma cultura. Isso também acontece com os "metamorphis", onde se obseva, de acordo com Sutton-Stence (2007, p. 46) "a deliberately seamless blending

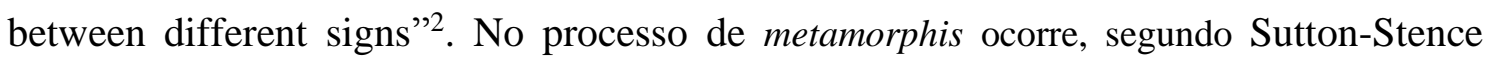
(2007) uma combinação perfeitamente integrada entre diferentes sinais e os alfabetos datilológicos, que podem ser realizados com as duas mãos, ou por meio de configurações simbólicas de mãos, como "the 'ILY' sign in ASL that represents I-LOVE-YOU" (SUTTON-SPENCE, 2007, p.46) ${ }^{3}$. Além das temáticas encontradas na literatura surda, que revelam o folclore das comunidades surdas, Sutton-Spence (2007, p. 46), fazendo referência a Carmel (1996), conclui que:

[... sign language is a central element of Deaflore, which suggests that native sign language play will form a central element of that native group's Deaflore. This in turn may produce evidence relevant to Carmel's central interest of whether Deaflore is an international phenomenon or one that is globally interlinked but also displays clearly separate expression belonging to individual sign language communities ${ }^{4}$. 
Portanto, sendo a língua de sinais o elemento central do folclore surdo (Carmel, 1996), nosso olhar sobre a literatura produzida por surdos requer uma análise dos elementos linguísticos que delimitam a estética das narrativas em línguas de sinais.

\section{A estética e as narrativas surdas.}

Em qualquer língua, a Estética é um elemento de sedução nas produções literárias. A Literatura é uma forma artística da linguagem e, assim como o texto literário, todas as artes trazem na forma um elemento de sedução. O prazer suscitado pela forma tem um papel fundamental: prender a atenção do fruidor, já que "não há nenhuma razão para prolongar o contato com o um objeto estético que não proporcione nenhuma satisfação" (JOUVE, 2012, p.45). Essa convicção de que o prazer é essencial para a experiência estética está na base da abordagem de Schaeffer, que apresenta a percepção estética como uma "atividade cognitiva regulada por seu índice de satisfação interna" (2000, p.49). Por ser uma atividade cognitiva, a estética, diante da arte literária, tem uma funcionalidade, que é levar o fruidor a uma satisfação concomitante à percepção, e não à satisfação obtida posteriormente. Segundo Jouve (2012, p.47) "podemos, então, afirmar que toda obra considerada hoje como literária foi, em dado momento, acolhida como esteticamente bem-sucedida".

Os elementos estéticos presentes nas obras artísticas, dentre elas as literárias, podem estar relacionados tanto às regras de um grupo de obras de determinada época, como também podem estar relacionados a elementos estéticos de forma linguística ou imagética. Sabendo que a literatura se apropria da forma estética e do conteúdo semântico-cultural para cumprir seu papel de produzir arte no campo da linguagem (escrita ou oral), pretendemos refletir sobre como as narrativas surdas fazem essa apropriação, transformando o uso dos elementos linguísticos existentes nas línguas de sinais em formas estéticas que caracterizam as produções literárias da comunidade surda.

Conforme Ryan (1993, p.145), a narração de histórias, presente em todas as culturas, é a melhor e mais elementar forma de comunicação entre os homens. As narrativas permitem atividades mentais peculiarmente humanas tais como: formar experiências intuitivas e reconhecer padrões e formas linguísticas. Historicamente, as narrativas serviram para transmitir relatos dos mitos sobre deuses, histórias de heróis, 
anedotas sobre pessoas comuns, lições da natureza e fábulas. Em relação às narrativas encontradas na Língua de Sinais Americana - ASL, Ryan argumenta que as narrativas combinam gestos, mímicas, sinais e expressões faciais e observa que as narrativas em ASL podem ser comparadas a uma imagem visual do relato. As narrativas fornecem uma estrutura para a perspectiva de visão de mundo do povo surdo "without air, our cells die; without ASL storytelling, our (Deft) selves die" 5 (RYAN, 1993, p.145).

Ainda segundo Ryan (1993, p.145), as narrativas normalmente tratam de temas sobre as pessoas surdas, suas experiências e sua relação com pessoas não-surdas, onde é possível perceber jogos de sinais e trocadilhos. Os contadores de história não se diferenciam muito em suas características essenciais. Contadores de histórias surdos costumam trabalhar com vários recursos estético-linguísticos numa mesma história.

Com relação à funcionalidade das narrativas em ASL, Ryan (1993) apresenta algumas delas. O autor cita que a contação de histórias melhora a competência comunicativa dos aprendizes (surdos e não surdos), melhora a sensibilidade cultural, ajuda os aprendizes de língua de sinais, como segunda língua, a ter uma aprendizagem mais eficaz quando aprendem através das histórias narradas, desenvolve as habilidades de atenção, possibilitando a prática de habilidades como: criatividade, imaginação e visualização, além de expor os aprendizes aos valores culturais e aos valores do sistema. Além dessas funcionalidades Ryan (1993) descreve a importância das histórias contadas em ASL, afirmando que as narrativas em ASL são valiosas para familiarizar novos aprendizes com a literatura disponível e com a cultura surda existente no mundo, levando-a para o mundo. Ryan (1993) ainda afirma que as histórias em ASL criam laços entre os aprendizes e os contadores de histórias, fornecendo informações e conhecimentos valiosos, provocando no aprendiz o uso de sua imaginação para ver através da imagem criada pelos olhos da mente, além de servirem de diversão.

Portanto, diante deste apanhado teórico sobre a Literatura, a Linguagem, a Literatura Surda, a Estética das Narrativas Surdas, resta-nos analisar as narrativas selecionadas para detectar os elementos estético-linguísticos produzidos pelos contadores de histórias durante suas narrativas. 


\section{Metodologia}

O corpus deste trabalho se constitui de narrativas de surdos contadores profissionais de histórias, coletadas na internet. A primeira narrativa é $O w l$ (Coruja) de Carter, poeta surdo, britânico, professor da Universidade de Bristol, no Reino Unido. A segunda narrativa é Bolinha de Ping-Pong produção de Segala, contador de histórias surdo, brasileiro, ator em companhias de arte e produções artísticas no Brasil.

Owl é um vídeo de 6 minutos e 59 segundos de duração. Bolinha de Ping- Pong é um vídeo de 3 minutos 40 segundos de duração. Ambas as produções são narrativas realizadas por contadores de histórias surdos. Owl é uma narrativa em BSL e Bolinha de Ping-Pong é uma narrativa em LSB. Para fins de reconhecimento do material a ser analisado, assistimos três vezes a cada vídeo. Em seguida, numa quarta visualização, listamos os elementos estético-linguísticos propostos que aparecem nos dois vídeos.

\section{Processos linguísticos encontrados nas narrativas surdas}

Nesta seção vamos analisar dois dos processos linguísticos encontrados nas narrativas analisadas, cujo reconhecimento e definição foram apresentados em estudos de vários autores que pesquisam a Literatura Surda, como Sutton-Spence e Napoli (2010); Sutton-Spence (2013); Sutton-Spence e Kaneko (2007); Bahan (2006); Machado (2013) e Pimenta (2012).

\subsection{O antropomorfismo}

O processo linguístico de maior destaque, facilmente reconhecível é o antropomorfismo, que consiste na incorporação de referentes animados ou inanimados, não humanos. Este recurso linguístico está presente em grande parte das línguas de sinais conhecidas e explora a habilidade de usar o corpo e seus membros (principalmente os superiores) ao expressar aparências, sentimentos e comportamentos dos referentes envolvidos na história, atribuindo-lhes traços humanos.

Não se trata de mímica, pois essa usa o corpo inteiro, tem uma duração extensiva para representar a imagem e o espaço é explorado por todo o corpo, funcionando como espelho. $\mathrm{O}$ antropomorfismo utiliza o corpo acima dos quadris e usa o movimento das mãos e dos braços para explorar o espaço, imprimindo um recorte menor do que a mímica, além de permitir a incorporação de mais de um referente ao 
trocar o espaço de sinalização enquanto a mímica se centraliza na incorporação de apenas um referente por vez. Sutton-Spence e Napoli (2010) observam que os contadores de história utilizam alguns parâmetros para representar o antropomorfismo e sugere uma escala para esse processo, a qual depende de fatores como: habilidades e intenções do sinalizador, a animalidade das entidades representadas, a forma de seus corpos e a forma do vocabulário usado para se referir a essas entidades.

Para fins de análise dos trechos nas narrativas cabe, neste momento, uma melhor definição de "antropomorfismo" e de "incorporação", com o objetivo de diferenciar esses dois conceitos. A incorporação é o processo de transpor referentes da história, animados ou inanimados, para o corpo do ator ou do contador de histórias. A mímica utiliza essa habilidade humana, a da imitação corporal, entretanto, é preciso observar que, nas narrativas surdas, as incorporações através da língua de sinais e a mímica conservam diferenças pontuais e não podendo ser considerado a mesma atividade. Já o antropomorfismo, como o próprio nome já mostra, antropo - homem, morfia - forma, também é um processo de transpor referentes, mas com o objetivo de usar a criatividade e a língua para dar forma humana a alguns dos referentes da narrativa, animados e inanimados (objetos, animais, alimentos, etc.). Vamos analisar apenas os momentos em que ocorre a transposição mórfica dos referentes não humanos.

Em Owl encontramos um total de noventa incorporações, sendo seis de diferentes seres animados humanos: a mãe, o menino, a professora, os colegas de classe, o colega de classe à esquerda e o lixeiro; e um ser animado animal, a coruja, referente que sofre o processo de antropomorfia. Grande parte da narrativa é percebida pelo processo de incorporação. Para fazer as incorporações, o contador surdo usou o critério de mudança de espaço incorporado, com a mudança da direção do olhar. A cada mudança de espaço ou mudança da direção de seu olhar, uma incorporação acontecia, introduzindo um novo referente ou retomando um referente introduzido anteriormente na narração.

As características corporais destacadas nos referentes não humanos, no caso a coruja, são selecionadas pelo contador a partir de suas perspectivas, para a comunicação com os alunos. Os surdos se comunicam com as mãos e, dessa forma, as asas seriam a parte do corpo animal que correspondem às expectativas dessa forma de comunicação. No diálogo com os alunos, a coruja diz que devem estudar, ler, usando expressões 
faciais apropriadas para o contexto de uma aula. O contador usa a antropomorfia para incorporar expressões faciais humanas à coruja. As figuras de 1 a 6 mostram incorporações humanas:

Figura1 - Mãe

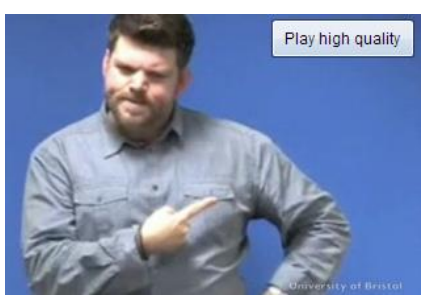

Figura 4 - Colegas

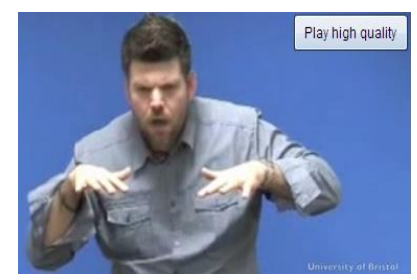

Figura 2 - Menino

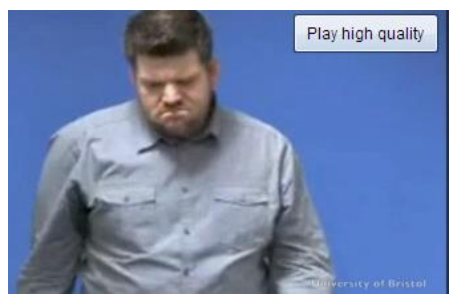

Figura 5 - Colega

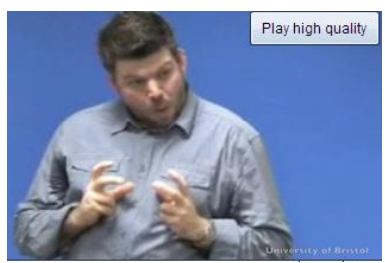

Figura 3 - Mestra

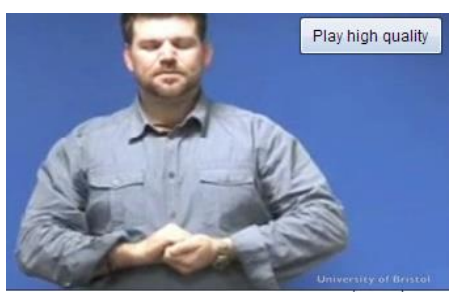

Figura 6 - Lixeiro

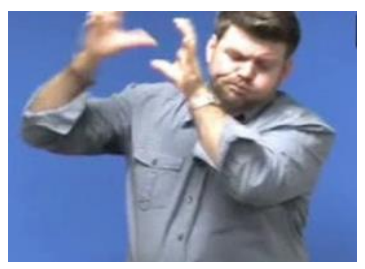

Na figura 7, é possível se observar a antropomorfia do referente "coruja", ser animado, não-humano:

Figura 7 - Coruja

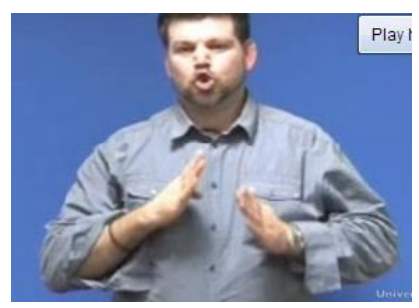

É a habilidade do contador de histórias, portanto, que determina a incorporação de cada referente. $\mathrm{Na}$ representação dos referentes humanos, notamos que a forma corporal descreve a característica física predominante em cada um deles. Além das características corporais, também são representadas as emoções predominantes, 
atribuídas a cada personagem, bem como a variação dessas emoções ao longo da narrativa, a depender do contexto discursivo.

$\mathrm{Na}$ incorporação da coruja, notamos que o elemento físico desse animal, destacado pelo contador, foram suas "asas" que assumem o lugar das mãos, símbolo da comunicação nas línguas de sinais, usadas para a sinalização. Percebemos uma mesclagem entre a forma "mão humana" e a forma "asa" do animal, confirmando, portanto, o processo de antropomorfismo na incorporação da coruja.

Outro momento de antropomorfia ocorre quando a coruja "pisca" para os alunos, indicando que está viva e poderá ajudá-los. Nesse momento, a forma de piscar não é a forma animal e sim a forma humana, estabelecendo um pacto de silêncio entre um e outro referente (no caso, entre a coruja e os alunos surdos), ou ainda, indicando que algo inesperado poderá acontecer, para surpresa dos envolvidos na cena (o fato da coruja iniciar a sinalização). As figuras 8 e 9 mostram as incorporações antropomórficas na representação das "asas"” no "piscar" da coruja:

Figura 8 - Asas

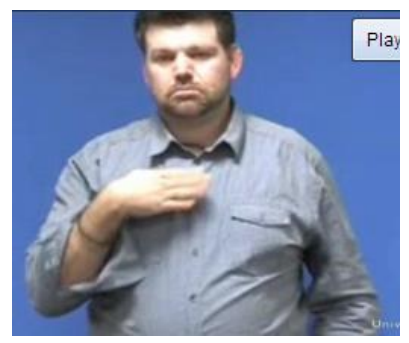

Figura 9 - Piscar

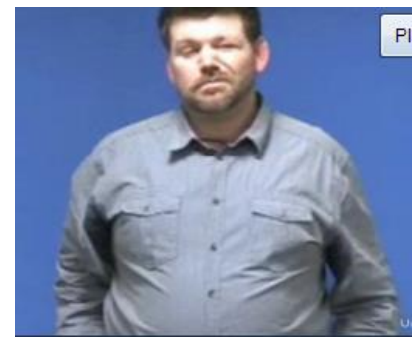

A antropomorfia apresentada na narrativa pode ser compreendida como um processo criativo linguístico, pois recorre a uma configuração de mãos "mesclada", que reúne uma característica animal (asas) a uma característica do ser humano surdo, que usa as mãos para se comunicar. Além da configuração de mãos, têm-se as expressões faciais, transferidas da natureza expressiva humana para o animal.

Em Bolinha de ping- pong, grande parte da história é contada com o uso do processo de incorporação e a representação antropomórfica realiza-se pela incorporação do referente inanimado, a bolinha. Encontramos um total de quarenta e sete incorporações, sendo cinco de seres animados-humanos diferentes: o jogador A, o 
jogador B, o juiz, a platéia, os jogadores e uma de um ser inanimado-objeto: a bolinha. Para se determinar a quantidade de incorporações na narrativa, usou-se critério semelhante ao usado na narrativa anterior, quanto à mudança de espaço ou da direção do olhar.

Nessa narrativa o contador surdo começa estabelecendo todos os referentes no espaço de sinalização. No mesmo momento que estabelece o referente, também imprime a caracterização corporal e emocional de cada personagem da história. $\mathrm{O}$ contador surdo usa as mesmas incorporações ao longo de toda história e apenas no final inverte a característica emocional da bolinha, que inicia a competição muito feliz e termina pedindo socorro ao juiz, que a salva da situação de violência.

Quanto à habilidade de incorporar cada referente, percebemos que dentre os personagens humanos, apenas o juiz se comunica em língua de sinais com a bolinha. Os demais personagens são representados pelas realizações incorporadas do contador. As figuras de 10 a 14 expõem as incorporações humanas presentes na narrativa:

Figura 10 - Jogadores

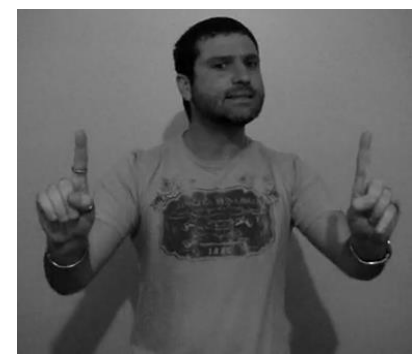

Figura 11 - Jogador B

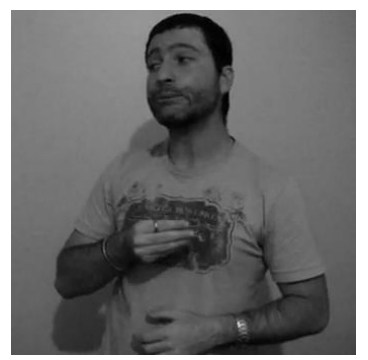

Figura 12 - Jogador A

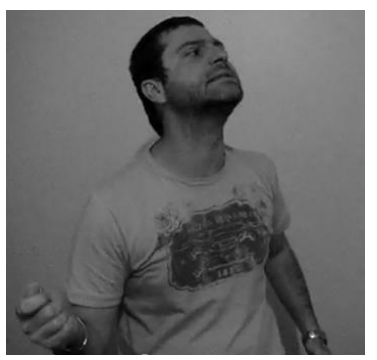

Figura 13 - Juiz

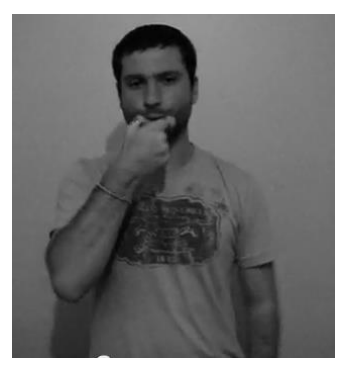

Figura 14 - Plateia

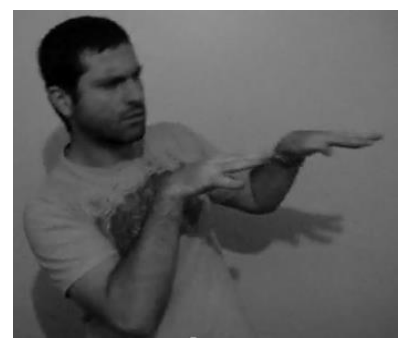

No caso da incorporação da bolinha, percebemos, mais uma vez, que o contador surdo usa a cabeça para realizar o processo antropomórfico. A bolinha é batida e rebatida várias vezes pelos jogadores. Tanto no início, quando ela se comunica com o 
juiz, demonstrando alegria, como no final, ao lhe pedir que a salve, o contador dá vida à bolinha, atribuindo-lhe características humanas para a comunicação, ou seja, ela tem "mãos". A bolinha pede ajuda usando gestos próprios das mãos humanas e se comunica usando a língua de sinais. Ora, um objeto de forma perfeitamente esférica não apresenta nenhuma saliência que possa ser tomada como "mãos" para sinalizar. Assim, o contador, não podendo mesclar características do objeto às características humanas, usa sua criatividade linguística e opta por atribuir "mãos" humanas a um objeto inanimado.

O momento mais evidente do processo de antropomorfia apresentado pelo contador é quando ele representa em movimento lento o sentimento e a forma como a bolinha é batida e rebatida. No momento em que o contador focaliza a bolinha ele a incorpora usando de antropomorfia, mesclando a forma circular da bola ao formato também circular da cabeça de um ser humano. O contador utiliza sua própria cabeça e suas expressões faciais para representar os sentimentos humanos atribuídos à bolinha naquela situação. Nas figuras 15 e 16, mostramos a incorporação antropomórfica da "bolinha", referente inanimado-objeto.

Figura 15 - Bolinha pede ajuda com mãos que sinalizam

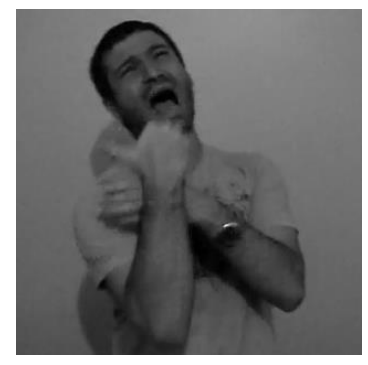

Figura 16 - Bolinha em movimento

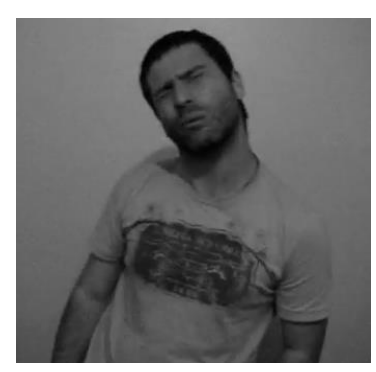

O processo de antropomorfia evidencia outros elementos linguísticos, que podem ser usados de forma produtiva na narrativa, concatenados à incorporação, tais 
como: o uso do espaço, a velocidade de sinalização, a simetria, a direção do olhar, e o uso de classificadores.

\subsection{Espaço metafórico}

Nas línguas de sinais, o espaço gramatical está presente desde a formação fonológica do sinal até o nível sintático (AGUIAR, 2013; QUADROS e KARNOOP, 2004). Entretanto estudos sobre as produções literárias de surdos apontam para o uso metafórico do espaço de sinalização (SUTTON-SPENCE, 2013).

Conforme Sutton-Spence (2013, p.50), as línguas orais e as línguas de sinais apresentam mecanismos distintos para construir metáforas. Enquanto os falantes de línguas orais relacionam o sentido de "crescimento" a palavras com sentido de "força" e "saúde", o usuário de línguas de sinais marcará o sentido metafórico por meio do uso do espaço. Nas línguas faladas o conceito de metáfora constrói o sentido a partir da iconicidade da imagem e perde parte da forma visual ao ser apropriado pela língua falada ou escrita. Nas línguas de sinais, o sentido icônico parece ser transferido para a divisão do espaço adotada para realizar a língua de sinais, deixando pistas do sentido icônico para além do sentido por representar a forma visual deste sentido. Os estudos de Sutton-Spence (2013) mostram que, nos poemas sinalizados, os poetas surdos, considerando suas perspectivas sobre a identidade dos Surdos, dispõem de seus sinais e os movem em posições de oposição espacial, como esquerda-direita, acima-abaixo, adiante-atrás, tornando essas polaridades metaforicamente significativas.

Em $O w l$, percebemos o uso metafórico do espaço. Em grande parte da narrativa o eixo vertical, com movimentos para cima e para baixo, é preenchido pela relação espacial concreta, como apresentada nos diálogos entre: alunos e professora (professora em pé, alunos sentados); menino e mãe (menino de estatura baixa, mãe alta); menino e lixeiro (menino estatura baixa, lixeiro alto). Ao se considerar a diferença entre a altura das crianças e a dos adultos, espera-se que o espaço seja marcado com a sinalização acima e abaixo, adequada aos referentes e suas idades.

Quando a coruja aparece na história, sendo ela usuária de língua de sinais, forma de comunicação que durante parte da história foi perseguida e, até mesmo, proibida, ela é colocada sobre o armário, numa posição mais elevada. Ao retornarem à escola, no dia seguinte, os alunos se dão conta da falta da coruja. Os alunos buscam entender onde está 
a coruja, mas ao usar a oralidade labial para explicar os alunos não entendem e o narrador transfere a insatisfação emocional dos alunos por sinalizar no eixo horizontal central-abaixo. Denotando assim o uso metafórico do espaço pra indicar o sucesso emocional dos alunos com a presença da coruja - plano acima - e o fracasso dos alunos, agora, sem a coruja - plano abaixo. Observe o espaço metafórico representado na sequência das figuras 17 a 20 .

Figura17 - Professora coloca a coruja sobre o armário intérprete

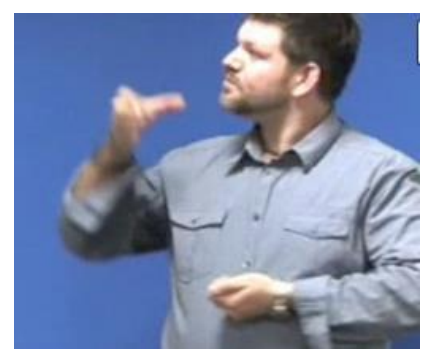

Figura 18 - Alunos olham a coruja

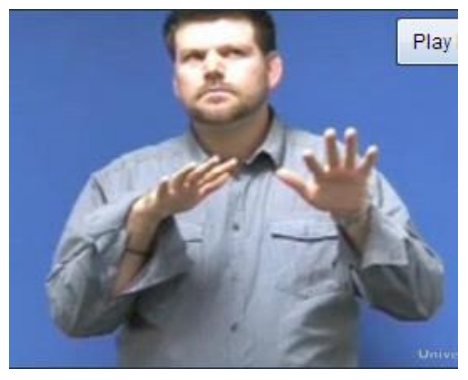

Figura 19 - Alunos olham assustados, pois a coruja sumiu

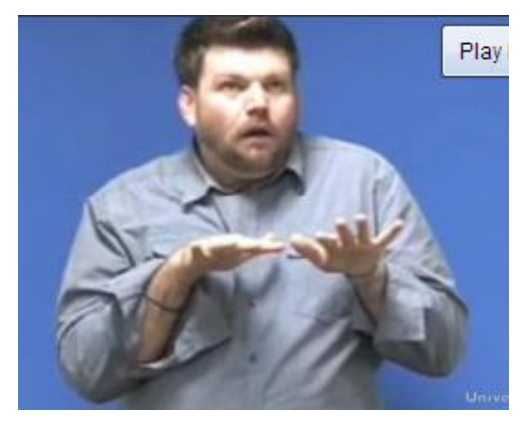


Figura 20 - Alunos olham para a professora

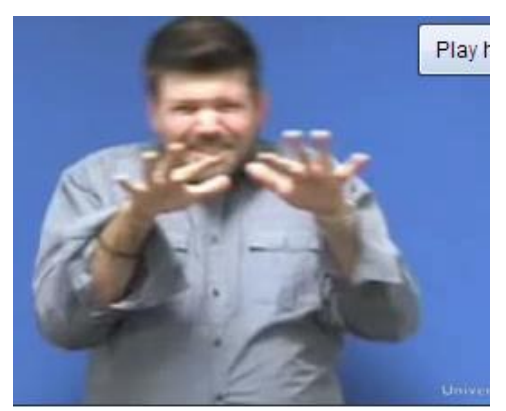

Na sequência das figuras 19 e 20, notamos a disposição corporal e o espaço de sinalização para indicar o fracasso no entendimento das orientações da professora, em contraste com o espaço de sinalização definido para as orientações da coruja, que é usuária da língua de sinais. Essas escolhas indicam a marcação das relações da comunidade surda e dos espaços sociais que ocupam, nesse caso, a escola.

Em Bolinha de ping-pong, notamos a divisão do eixo espacial em três partes: lado esquerdo, lado direito e centro. No início da narração o contador deixa claro que ambos os lados, direito e esquerdo, estão relacionados aos jogadores, que têm características corporais diferentes, mas um mesmo objetivo: vencer. Não se está diante de um confronto entre o bem e o mal, mas observando dois competidores que querem vencer. No centro, tem-se o equilíbrio, a neutralidade, a idéia de que não haverá, necessariamente, um vencedor, como pode ser observado nas figuras 21 e 22 :

Figura 21 - Divisão do espaço (esq/dir): jogadores

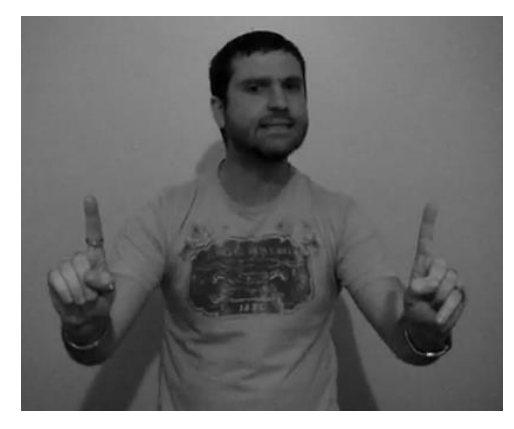


Figura 22 - Marcação do espaço central: juiz

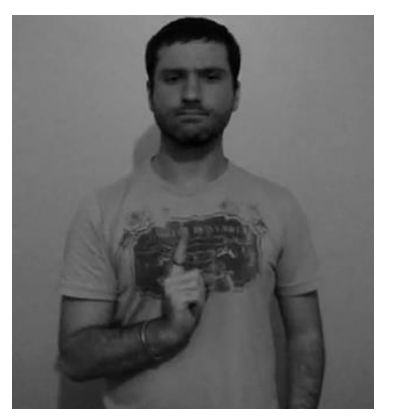

O contador de histórias pode determinar as relações metafóricas que pretende usar ao longo da história. É possível estabelecer algumas regras, tais como: o lado direito é o lado do bem e o lado esquerdo, o lado mal, ou ainda, o "acima" (céu) é espaço benéfico, o "abaixo" (inferno), espaço maléfico. No entanto, embora tradicionalmente o "acima" seja relacionado a aspectos positivos e o "abaixo", a aspectos negativos, o contador de histórias pode quebrar essa expectativa e estabelecer novos significados para as relações espaciais. Nas narrativas, a metaforização do espaço ocorre menos frequentemente do que na poesia, mas esse elemento, o espacial, pode ser encontrado agregando significados semânticos aos referentes.

\section{Considerações finais}

Ao analisar a Literatura Surda disponível em vídeos na Internet, notamos que o estudo dessas produções pode elucidar alguns aspectos linguísticos e literários dessa forma de manifestação literária. O gênero narrativo tende a apresentar muitos elementos estético-linguísticos, mas a antropomorfia é um destaque que deixa transparecer o uso criativo do contador sobre os domínios linguísticos de sua língua. Podemos perceber que as narrativas exigem do contador de histórias uma contextualização mais clara, sem enigmas ou mensagens subliminares, a princípio. Há uma história, há uma sequencia de fatos que precisa ser a base para a mensagem no fundo. Assim fica evidente a opção de incorporações de todos os referentes que precisam ser apresentados ao expectador da história. O processo antropomórfico nas incorporações de referentes animados não humanos, como em $O w l$ ou inanimados, como em Bolinha de ping-pong, apresenta "brilho" criativo da narrativa. 
O espaço metafórico é um elemento consideravelmente estudado nos poemas surdos. Nas narrativas, contudo, ele surge como uma escolha natural do contador, que não o estabelece propositalmente. Parece haver uma sincronia semântica que metaforiza o espaço considerando os eixos: vertical, horizontal, e ainda, o eixo diagonal de sinalização espacial. Vimos nas narrativas analisadas que a metáfora espacial é sutil, porém, suficiente para que o espectador tenha clareza ao perceber os aspectos negativos, positivos ou neutros, como no caso da narrativa Bolinha de ping-pong. Podemos observar que o antropomorfismo e o espaço metafórico, processos estético-linguísticos analisados neste trabalho, contribuem para transmitir as perspectivas da comunidade surda sobre suas relações com os não participantes dessa comunidade e o eterno culto e louvor a sua amada língua de sinais, como demonstrado na narrativa $O w l$.

Em Bolinha de ping-pong, a princípio podemos pensar que não há, explicitamente, um tema ligado ao folclore surdo. No entanto, tem-se uma metáfora, no sentido dos eventos ocorridos com a bolinha. A comunidade surda e suas aspirações sobre o melhor modelo de educação de surdos, respeito a sua língua e sua diferença cultural são, muitas vezes, motivo de disputas entre as ideologias que se constroem em torno do melhor modelo de educação, do reconhecimento da língua de sinais como língua e da existência de uma cultura surda. Relações de poder, experimentadas por toda comunidade surda, são recorrentes nos diversos países em que há movimentos surdos expressando essas aspirações. Caso a metáfora seja compreendida, torna-se evidente a presença do folclore surdo na narrativa. Além disso, os elementos estético-linguísticos dessa história, as incorporações e os movimentos executados em velocidade lenta chamam atenção para a situação de dúvida que pode ser apresentada a vida de qualquer ser humano. Na comunidade surda isso pode ser interpretado pela indefinição de identidade, ou pela situação da educação de surdos que já passou por tantas propostas fracassadas e permitindo uma referência à disputa entre educadores e comunidade surda a respeito da melhor forma de educar alunos surdos.

Há outros elementos que compõem os processos-linguísticos na literatura os quais não foi possível apresentar neste trabalho tais como: simetria, direção do olhar, velocidade, dentre outros, que poderão ser analisados em trabalhos futuros. Em nossa análise percebemos que as incorporações e a antropomorfia nas narrativas são muito presentes, embora o processo de antropomorfia receba destaque. Para a conclusão de 
que a antropomorfia é um processo básico nas narrativas em língua de sinais, precisamos apenas de dados quantitativos. Os processos de incorporação e antropomórficos são fundamentais para estética literária dessas narrativas, considerando-se que um único processo abarca muitos elementos linguísticos como: classificadores, incorporação, uso do espaço, expressões faciais, direção do olhar.

Percebemos também que, de posse de um número maior de narrativas, será possível, em estudos posteriores, perceber quais são as características gerais do gênero narrativo, na Literatura Surda e inferir, a partir de tais características, quais os processos estéticos predominantes. Acreditamos que novas análises das produções literárias dos artistas surdos poderão se aproximar dos valores essenciais dessa comunidade, além de expor os mecanismos criativos da linguagem literária em línguas de sinais.

\begin{abstract}
The language of a community presents linguistic processes, built by its subjects, to communicate and share impressions and expressions about life. The Deaf Literature uses sign language to reflect themes and linguistic-cultural forms of the Deaf community, a community that expresses itself through visuality and the body. Based on the Sutton-Spence and Napoli studies on anthropomorphism and the metaphorical space in the Deaf Literature, this article analyzes two narratives produced by deaf storytellers in LSB, Sign Language Brazil and BSL, British Sign Language, trying to identify these two linguistic processes, anthropomorphism and metaphorical space. In the analysis of the narratives we use the identification of processes and their quantification. This study demonstrates that the process of anthropomorphism, based on incorporations, is the most recurrent in the analyzed narratives. The metaphorical space appears subtly, but may be present depending on the spatial division attributed by the storyteller.
\end{abstract}

Keywords: Deaf Literature. Narratives in LS. Anthropomorphy. Metaphorical space.

\title{
Resumen
}

La lengua de una comunidad presenta procesos lingüísticos, construidos por sus sujetos, para comunicar y compartir impresiones y expresiones sobre la vida. La Literatura Surda utiliza la lengua de signos para repercutir temas y formas lingüísticas-culturales de la comunidad Surda, una comunidad que se expresa por medio de la visualidad y el cuerpo. En cuanto a los estudios de Sutton-Spence y Napoli sobre el antropomorfismo y el espacio metafórico en la Literatura Surda, este artículo analiza dos narrativas producidas por contadores de historias sordas en LSB, Lengua de Signos del Estado, Brasil y BSL, Lengua de Señales Británica, buscando en ellas identificar esos dos procesos lingüísticos, la antropomorfia y el espacio metafórico. En el análisis de las narrativas nos valemos de la identificación de los procesos y su cuantificación. Este 
estudio demuestra que el proceso de la antropomorfia, basado en incorporaciones, es el más recurrente en las narraciones analizadas. El espacio metafórico aparece sutilmente, pero puede estar presente a depender de la división espacial asignada por el contador de la historia.

Palabras clave: Literatura Surda. Narrativas en LS. Antropomorfismo. Espacio metafórico.

\section{Referências}

AGUIAR, T. C. Nova proposta de sílaba em Libras. Dissertação (Mestrado em Letras) - Faculdade de Letras, UFG, Goiânia, 2013.

BAHAN, B. "Face to Face: Tradition in the American Deaf Community". In: BAUMAN, D.; ROSE, H.; NELSON, J,. Signing the Body Poetic. Berkeley, CA: University of California Press, 2006, p.21-50.

BASCOM W. R. Four functions of folklore. In A. Dundes (Ed.) The Study of Folklore, pp.279-298. Englewood Cliffs: Prentice-Hall, 1965.

CAMPELO, A. R. S. Aspectos da visualidade na educação de surdos. Tese (Doutorado em Linguística), Florianópolis, 2008.

CARTER, Richard. BSL poem "Owl", 2009.

Disponível em: https://youtu.be/aDFTIRSKXRg. Acesso em: 15 abr. 2018.

CARMEL, S. "Deaf Folklore. In: BRUNVAND, J. H., American Folklore: An Encyclopedia. London: Garland Publishing, 1996.

HOLANDA. Dicionário Aurélio de Português Online, 2017. Disponível em: 〈https://dicionariodoaurelio.com/folclore〉. Acesso em: 10 Nov. 2017

JOUVE, V. Porque estudar literatura?. Trad. Marcos Bagno e Marcos Marcionilo. São Paulo: Parábola, 2012.

MACHADO, F. A. Simetria na poética visual na língua de sinais brasileira. Dissertação (Mestrado em Tradução), Florianópolis: UFSC. 2013.

MOURÃO, C. H. N. Literatura surda: produções culturais de surdos em língua de sinais. Dissertação (Mestrado em Educação), Porto Alegre: UFRG, 2011.

PIMENTA, N. C. A tradução de fábulas seguindo aspectos imagéticos da linguagem cinematográfica e da língua de sinais. Dissertação (Mestrado em Tradução), Florianópolis: UFSC, 2012. 
QUADROS, R. M.; KARNOPP, L. B. Língua de sinais brasileira: Estudos linguíísticos. Porto Alegre: Artmed, 2004.

RAYN, S.. "Let's tell an ASL story". In: Gallaudet University Colleg for Continuing Education (ed). Conference Procedings. Washiton: DC. Gallaudet University press, Session 3, p. 145-150, 1993.

SCHAEFFER, J. M. Adieu a l' esthétique. Paris: PUF, 2000.

SEGALA, R. R.. Bolinha de ping pong, Cia. Arte e silêncio, 2009. Disponível em: https://www.youtube.com/watch?v=VhGCEznqljo . Acesso em: 25 nov. 2013.

SILVEIRA, R. M. H. Texto e diferenças. In: Leitura em revista. N.3. V. 2, p. 19-22. Janeiro-Junho, 2002.

STROBEL. Karin. As imagens do outro sobre a cultura surda. Florianópolis: Editora da UFSC, 2008.

SUTTON-SPENCE, R. e KANEKO, M. Symmetry in Sign Language Poetry. In: Sign Language Studies, V. 7, N. 3, pp. 284-318. Gallaudet University Press Spring, 2007.

SMITH, J. e SUTTON-SPENCE, R. What is the Deaflore of the British Deaf community, 2007.

SUTTON-SPENCE, R. e NAPOLI D. J. Anthropomorphism in Sign Languages: A Look at Poetry and Storytelling with a Focus on British Sign Language. In: Sign Language Studies, V. 10, N.4, pp. 442-475, Gallaudet University Press. Summer, 2010 .

SUTTON-SPENCE, R. "Spatial metaphor and expressions of identity in sign language poetry". In: Sign Language Studies, pp. 47-79, Gallaudet University, 2013. Disponível em: http://www.metaphorik.de/en/journal/19/spatial-metaphor-and-expressions-identitysign-language-poetry.html Acesso em: 24 nov. 2013.

\section{Notas}

1 [...] em primeiro lugar, para expressar a cultura do grupo, em segundo lugar para justificar o comportamento do grupo de pessoas de fora, em terceiro lugar para educar os membros do grupo sobre os valores e normas do grupo e em quarto lugar para manter essas formas esperadas de comportamento. Os quatro podem ser resumidos sob a função única de manter a estabilidade da cultura (tradução minha).

${ }^{2}$ uma mistura deliberadamente perfeita entre diferentes sinais (tradução minha).

${ }^{3}[\ldots]$ o sinal 'ILY' em ASL, que representa EU-TE-AMO (tradução minha). 
4 [...] a língua de sinais é o elemento central da Deaflore, o que sugere que o jogo de linguagem gestual nativa irá formar um elemento central do Deaflore. Esse, por sua vez, pode produzir provas relevantes para interesse central de Carmel de que o Deaflore é uma organização internacional ou um fenômeno globalmente interligado, além de também mostrar claramente expressões específicas pertencentes às comunidades de língua de sinais individuais (tradução minha).

${ }^{5}$ Sem ar, nossas células morrem; sem as narrativas nós surdos estamos mortos (tradução minha). 